\title{
Endogenous hydrogen sulfide can function as a relaxation factor in the bladder and prostate of male rats
}

\section{Suo Zou, Takahiro Shimizu, Shogo Shimizu, Youichirou Higashi, Hideaki Ono, Takaaki Aratake, Masaki Yamamoto, Tomoya Hamada, Yoshiki Nagao, Motoaki Saito}

Department of Pharmacology, Kochi Medical School, Kochi University, Japan

Background: Hydrogen sulfide $\left(\mathrm{H}_{2} \mathrm{~S}\right)$, an endogenous gasotransmitter, has a wide range of biological functions including neuromodulation, vasorelaxation and cytoprotection. In the lower urinary tract, however, physiological roles of $\mathrm{H}_{2} \mathrm{~S}$ have not been clarified in detail yet. In this study, we investigated (1) tissue distributions of enzymes related to $\mathrm{H}_{2} \mathrm{~S}$ biosynthesis [cystathionine $\beta$-synthase (CBS), cystathionine $\gamma$-lyase (CSE), 3-mercaptopyruvate sulfurtransferase (MPST), cysteine aminotransferase (CAT) and D-amino acid oxidase (DAO)], (2) endogenous $\mathrm{H}_{2} \mathrm{~S}$ levels, and (3) effects of $\mathrm{NaHS}$ (an $\mathrm{H}_{2} \mathrm{~S}$ donor) on contractility, in the bladder and prostate isolated from male Wistar rats. In addition, (4) effects of intravesically instilled GYY4137 (a slow-releasing $\mathrm{H}_{2} \mathrm{~S}$ donor) on the rat micturition were also investigated.

Methods: (1) Tissue distributions of these five enzymes were investigated by quantitative real-time PCR, Western blot analysis and immunohistochemistry. (2) Tissue $\mathrm{H}_{2} \mathrm{~S}$ contents were measured by the methylene blue method. (3) Effects of NaHS $\left(1 \times 10^{-9}\right.$ to $\left.3 \times 10^{-4} \mathrm{M}\right)$ were evaluated on carbachol $\left(10^{-5} \mathrm{M}\right)$-induced pre-contracted bladder strips and on noradrenaline $\left(10^{-5} \mathrm{M}\right)$-induced pre-contracted prostate strips, which were pretreated with propranolol $\left(10^{-6} \mathrm{M}\right)$ in order to prevent $\beta$-adrenoceptor-mediated relaxation. (4) In urethane-anesthetized ( $0.8 \mathrm{~g} / \mathrm{kg}$, ip) male Wistar rats, a catheter was inserted into the bladder in order to instill reagents $(2.4 \mathrm{ml} / \mathrm{h})$ and to measure intravesical pressure. After detecting 4 -5 micturition reflexes induced by saline instillation, GYY4137 solution $\left(10^{-8}, 10^{-7}\right.$ and $\left.10^{-6} \mathrm{M}\right)$ or vehicle was instilled.

Results: (1) MPST and CAT were detected in the bladder and prostate and CBS was only detected in the prostate, while CSE and DAO were undetectable in both tissues. Immunoreactvities of these enzymes were mainly detected in the urothelium and smooth muscle layer of the bladder, and in the prostate glandular epithelium. (2) $\mathrm{H}_{2} \mathrm{~S}$ was detected in both tissues. (3) NaHS dose-dependently induced relaxation of pre-contracted bladder and prostate strips. (4) Intravesically instilled GYY4137 significantly prolonged intercontraction intervals.

Conclusions: $\mathrm{H}_{2} \mathrm{~S}$ can function as an endogenous relaxation factor in the rat bladder and prostate. Therefore, endogenous $\mathrm{H}_{2} \mathrm{~S}$ can be a potential therapeutic target for lower urinary tract dysfunctions such as overactive bladder and benign prostatic hyperplasia. 